\title{
Tristan Corbière, Gli amori gialli
}

\section{Maria Emanuela Raffi}

\section{(2) OpenEdition}

\section{Journals}

\section{Edizione digitale}

URL: http://journals.openedition.org/studifrancesi/4440

DOI: $10.4000 /$ studifrancesi.4440

ISSN: 2421-5856

\section{Editore}

Rosenberg \& Sellier

\section{Edizione cartacea}

Data di pubblicazione: 1 settembre 2016

Paginazione: 356-357

ISSN: 0039-2944

\section{Notizia bibliografica digitale}

Maria Emanuela Raffi, «Tristan Corbière, Gli amori gialli », Studi Francesi [Online], 179 (LX | II) | 2016,

online dal 01 septembre 2016, consultato il 18 septembre 2020. URL : http://journals.openedition.org/ studifrancesi/4440 ; DOI : https://doi.org/10.4000/studifrancesi.4440

\section{Questo documento è stato generato automaticamente il 18 settembre 2020.}

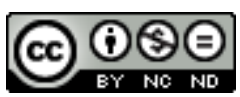

Studi Francesi è distribuita con Licenza Creative Commons Attribuzione - Non commerciale - Non opere derivate 4.0 Internazionale. 


\title{
Tristan Corbière, Gli amori gialli
}

\author{
Maria Emanuela Raffi
}

\section{NOTIZIA}

TRISTAN CORBIÈRE, Gli amori gialli, edizione italiana a cura di Luca Salvatore, introduzioni di Lorella Martinelli e Renzo Paris, con una nota di Mario Richter e un saggio di Giovanni Bogliolo, testo francese a fronte, Novara, Arcipelago Edizioni, 2015, LXXIV + 793 pp.

1 Questa edizione italiana delle opere di Corbière realizzata da Luca SALVATORE, già efficace traduttore di Lautréamont, corredata di un imponente apparato di annotazioni - «Forgerie corbérienne» pp. 405-661 -, si presenta arricchita, a sottolineare l'importanza dell'impresa, anche da un inconsueto numero di presentazioni da parte di diversi critici. A cominciare, naturalmente, da quella del traduttore e curatore («Mal visti mal detti»), che riflette sul concetto di "modernità" tanto variamente utilizzato dalla critica per la seconda metà dell'Ottocento e sul suo rapporto con la poesia: «il lirico, e con esso le nuove istanze che il Moderno ha reso ineludibili, ha bisogno di altri lettori, che solo l'epoca seguente gli avrebbe fornito». L'anacronismo strutturale dei poeti della seconda metà del xIx secolo, la loro oscurità per i contemporanei, ha tuttavia dato vita, attraverso una rivolta «totale, inesorabile», alla poesia futura fatta, soprattutto per Corbière, di «immagini visive» e dell'«iconicità di una scrittura, amorale ed emotiva».

2 Immediatamente di seguito Lorella MARTINELLI fornisce in Tristan Corbière, il poeta in contumacia un vero e proprio ritratto di Corbière e della sua opera, di cui identifica il «nucleo vitale» nella «carica eversiva dello stile», che finisce con l'esprimersi «nel ghigno e nella parodia». Les Amours jaunes in particolare, anche grazie al ventaglio semantico-simbolico che il colore suggerisce, appaiono come la rappresentazione poetica di una «posa» formata da una successione di maschere ed espressione di un sostanziale vuoto di identità, conformemente alla celebre dichiarazione di poetica di Corbière: «Artiste sans art, - à l'envers». Particolarmente significativa appare all'A. la 
poesia Le poète contumace in cui si rivela appieno la vocazione all'isolamento e all'esilio dell'autore, ma anche la sua propensione per il «manque», riempito solo fuggevolmente, in alcune zone della raccolta, dalla visione della terra bretone, dal labile mondo del sogno, da una ricerca verbale sempre effimera e contraddittoria.

3 Renzo PARIS racconta in chiave piacevolmente e appassionatamente autobiografica (Il dandy sciamano) il suo primo incontro da traduttore con i testi poetici di Corbière e il suo successivo lungo percorso di studioso e biografo del poeta bretone. Percorso molto concreto, costruito su viaggi, incontri, letture, aneddoti, ritratti e fotografie fino alla riflessione sulla sua enigmatica morte. Ne emerge il ritratto di quello che Paris definisce «il poeta sciamano»; e dello sciamano riconosce in Corbière le caratteristiche: «Si veste a suo modo, costruisce accanto a lui i punti cardinali del suo universo, la sua cosmogonia [...] rimane immerso tutto dentro una civiltà orale». Con questa vocazione all'oralità la poesia di Corbière si trova continuamente a fare i conti, sottraendosi ad un tempo alla rima, all'onomatopea, alla pagina bianca per cercare un ritmo «modernissimo, un rap dissonante, materico», uno «spezzatino lirico» da cui emerge potentemente una «violenta parodia della vita».

Nella sua nota critica L'Arte non mi conosce. Io non conosco l'Arte, Mario RICHTER percorre le coordinate letterarie e soprattutto poetiche in cui Les Amours jaunes vanno collocate e comprese, anche nella loro dirompente novità formale. Per rendere il senso della continuità spezzata che lega Corbière a Baudelaire e a Rimbaud, Richter segue le trasformazioni della metafora della nave dall'Albatros al Cour supplicié al Bossu Bitor, attraverso un progressivo smantellamento dell'«essenziale e composta espressione» di Baudelaire fino alla "particolare luce "gialla"» di Corbière - di cui Salvatore appare profondamente consapevole -, fatta di una lingua e di una punteggiatura estremamente tormentate.

5 Il Corbière dei traduttori italiani di Giovanni BogloLo entra nel vivo della traduzione delle Amours jaunes. Già proposto nel 1975, il saggio traccia le vicende fino a quella data delle traduzioni italiane della poesia di Corbière, vicende non brillantissime a parte qualche piccola eccezione che dimostra una maggiore sensibilità, come nel caso di Enzo Siciliano e Renzo Paris (1972) e nella traduzione definita dal suo autore «derivazione espressiva» di Claudio Rendina (1973). L'Addendum 2015 che Bogliolo aggiunge per la presente edizione aggiorna lo studio delle traduzioni con otto nuove uscite, alcune molto parziali; fra di esse Bogliolo si interessa particolarmente alle traduzioni d'autore: Palmery, Bona e soprattutto Salvatore, mostrando numerosi esempi e difficili intrecci fra le due sensibilità poetiche a confronto, quella dell'autore e quella del traduttore. Nel caso di Salvatore, tuttavia, viene sottolineato anche l'enorme lavoro critico-filologico che precede e accompagna la ricostruzione dei testi di Corbière nella lingua italiana (la «Forgerie corbérienne» indicata all'inizio di questa scheda), facendone «il più ambizioso ed efficace esperimento di trasposizione in italiano della poesia di Corbière». 